\title{
A Psychological Perspective of Financial Panic
}

\author{
Anat Bracha and Elke U. Weber
}

\begin{abstract}
:
In spite of large number of financial crises, often depicted as episodes of financial panic, the notion of panic in financial markets is not very well understood. Many have argued that in order to understand financial crises, and in particular panic events, we need to go beyond classic economic arguments. This paper is an effort in that direction, in which we attempt to give a psychological account of panic and of panic in financial markets in particular, by discussing uncertainty, the desire for predictability and control, the illusion of control, and confidence. We suggest how one might incorporate these psychological insights into existing economic models.
\end{abstract}

\section{JEL Codes: D03, E32}

Anat Bracha is an economist in the research department at the Federal Reserve Bank of Boston. Elke U. Weber is the Jerome A. Chazen Professor of International Business at Columbia Business School and Professor of Psychology and Earth Institute Professor at Columbia University.

The views expressed in this paper are those of the authors only and do not necessarily represent the views of the Federal Reserve Bank of Boston or the Federal Reserve System.

This paper, which may be revised, is available on the web site of the Federal Reserve Bank of Boston at http://www.bostonfed.org/economic/ppdp/index.htm.

version of: September 2012 


\section{Introduction}

Kindleberger's classic book on financial panics (Kindleberger and Aliber 1978/2005), and recent books by Reinhart and Rogoff (This Time is Different 2009), and Akerlof and Shiller (Animal Spirits 2009) provide many examples of financial crises, often depicted as financial panics - from bank runs in the 19th century to the Great Depression, the East Asian Crisis, the dot-com collapse, and the Great Recession. Yet, in spite of the large number of such episodes, the notion of panic in financial markets is not very well understood.

According to the aforementioned books, in order to understand financial crises, and panic events in particular, we need to go beyond classic economic arguments. Specifically, we need to further explore "animal spirits," the expression used by Keynes (1936) to describe the human emotions that he saw as drivers of consumer confidence, necessary to motivate action. This paper is an effort in that direction, supported by a growing body of empirical research documenting the importance of emotional (or affective) determinants of decisions under risk and uncertainty, including financial investment decisions (for example, Holtgrave and Weber 1993; Loewenstein et al. 2001; Weber, Siebenmorgen, and Weber 2005). We attempt in this paper to give a psychological account of panic, and specifically of panic in financial markets, by discussing uncertainty, the desire for predictability and control, the illusion of control, and confidence. We suggest how one might incorporate these psychological insights into existing economic models.

Before diving into the psychology of panic, it is worth asking whether animal spirits are really necessary to explain financial crises regarded as panics. Couldn't such crises simply be instances of rational bubbles, that is, episodes where sophisticated investors are aware that a bubble exists yet, because of asymmetric information, constraints to arbitrage, or heterogeneous beliefs, do not drive prices down to fundamental values (Brunnermeier 2008)? For instance, rational investors may be aware of the bubble, but may prefer riding it rather than puncturing it in order to make profit in the short run. Indeed, the dot-com crisis of 2000 and the bubble 
preceding it provide an example that might be consistent with a rational bubble: a Barron's survey of professional money managers in 1999 revealed that 72 percent of the respondents believed the stock market to be in a speculative bubble. While the dot-com crisis may be explainable as a rational bubble, this does not appear to be the case with other major financial crises such as the 1997 East Asian Crisis and the 2008 Great Recession. Radelet and Sachs (2000) show that there was no awareness of any economic problem at the onset of the East Asian Crisis and that the crisis was not anticipated by key market participants; indeed, they called it "... the least anticipated crisis in years." Krugman (1998) also noted that he was caught by surprise, in spite of being less optimistic than most investors. Even scholars who identify political and economic factors as important contributors to the crisis cannot rule out panic as a driving cause (for example, Moreno 1998). Like the East Asian Crisis, the 2008 Great Recession does not seem to be consistent with a rational-bubble argument. Hard as it may be to believe now, Lehman Brothers' analysis in 2005 put only a 5 percent probability on the possibility that real-estate prices could go down (Foote, Gerardi, and Willen 2012, 18).

Not only did sophisticated investors fail to expect these crises, evidence also shows that they overreacted when the crises occurred. With the East Asian Crisis, there was a sudden withdrawal of investor funds from the region instead of a simple deflation of asset values where warranted (Radelet and Sachs 2000), and following the 2008 subprime mortgage crisis, investors avoided mortgage-backed securities altogether, regarding them as "toxic." This was reflected in tightened credit standards even for prime borrowers (Rosengren 2011, Figure 2, right panel) and in a complete breakdown of the securitization market for prime, nonconforming, "jumbo" mortgages, which are safe, low-default mortgages (see Figure 2 , left panel).

Having established that financial panics occur, we next ask what constitutes a panic. Financial panics have been described as a "sudden fright without a cause that may occur in asset markets" (Kindleberger and Aliber 2005, Ch. 5) and as "crises not justified solely on the basis of fundamentals" (Goldstein forthcoming). Bank runs are a special case of financial panic that have been characterized and modeled as caused by a "shift in expectations, which could depend on almost anything" (Diamond and Dybvig 1983) and that has negative consequences due to its 
self-fulfilling characteristic and its potential to amplify the effects of fundamentals on the economy (Goldstein forthcoming).

These descriptions depict panics as an emotional reaction with adverse consequences that is not (entirely) justified by existing market information. Interestingly, work on panic and animal spirits suggests that the mental models or "stories" that investors hold prior to a crash describing how the economy works or justifying the economic boom are key to understanding these episodes. For example, investors prior to the 1997-1998 East Asian Crisis referred to economic activity in that region as the "Asian Miracle." Prior to the 2008 subprime mortgage crisis, it was widely believed that real-estate prices would never fall. Once these models were challenged by empirical events to the contrary, panic resulted. In East Asia, when Thailand showed signs of trouble, foreign capital inflows quickly reversed, and other East Asian currencies were attacked. Once real-estate prices fell in 2008, the worst financial crisis since the Great Depression ensued. These stories or mental models are important, as they link uncertainty to confidence and then to panic, as further described below.

To preview our main point, we argue that the human need for predictability and control is central to a psychological account of panics. Confidence in a system such as a financial market results when investors believe they understand how things work, which leads to a sense of predictability (Einhorn 1986). This sense of predictability gives investors a feeling of control, which then legitimizes further opportunity seeking (reaping benefits while avoiding catastrophic losses) that is often riskier than it is perceived to be (Hertwig et al. 2004). We argue that events that destroy this sense of predictability and perceived control trigger panics, the feeling that crucial control has been lost and that the future is unpredictable, and hence, dangerous. Resulting behavior, including a retreat to safe and familiar options, aims to minimize exposure to such danger until a new model of how things work has been established.

We build our suggested psychological account of panic by starting with a description of human perception and reaction to risk and uncertainty as seen by psychology. We introduce and describe the concept of perceived control, and the difference between learning from description 
versus learning from experience in determining perception and choice under risk and uncertainty. We continue by discussing the illusion of control and its contribution to irrational exuberance or mania, and the flip side of it - the relationship between perceived lack of control and panic. Finally, we discuss economic models of panic and suggest how to incorporate the psychological insights introduced in this paper into existing economic models. We emphasize that our analysis is exploratory. It suggests a different way of thinking about financial panics and it is therefore meant to be provocative.

\section{Perceptions and reactions to risk and uncertainty}

The natural point of departure in the attempt to give a psychological account of panics to inform economics is a discussion of psychological models of decisionmaking under uncertainty. "Uncertainty" refers to a state in which decisionmakers are unable to specify the exact outcomes and their probabilities if they engage in different actions. The degree of this uncertainty can vary, with endpoints on a continuum that ranges from partial to full information about outcomes and their probabilities (Knight 1921). In economics this is represented by the probability distribution over future states of the world, where "decision under risk" refers to decisions made when the probability distribution over future states of the world is known and "decision under uncertainty" or "ambiguity" refers to decisions made when this probability distribution is unknown. The probability distribution over future states of the world is therefore key to analyzing decisionmaking under uncertainty.

\section{First departure from economic models-intuitive risk perception}

In contrast to the analytic, mathematical assessments of likelihood and severity of events used in economics, psychologists stress that risk perception is an intuitive assessment of such events and their consequences.

Evidence from cognitive, social, and clinical psychology indicates that risk perceptions are influenced by associative processes (meaning connections between objects or events contiguous in space or time, resembling one another, or having some causal connection (Hume 1748/1999)) 
and affective processes (that is, processes influenced by emotions) and that these influence risk perception as much or even more than analytic processes (Weber 2010). The psychologist Daniel Kahneman (initially in his Nobel address (2003) and more extensively in his recent book (2011)) has captured decades of behavioral research by characterizing two modes of thinking, called System 1 and System 2. The associative and affective processes that give rise to intuitive perceptions of risk are typical of System 1 thinking, which operates automatically and quickly with little or no effort and no sense of voluntary control and is available to everyone from an early age. Analytic assessments of risk, on the other hand, are typical of System 2 processes, which work by algorithms and rules such as probability calculus, Bayesian updating, and formal logic. System 2 processes must be taught explicitly and require conscious effort and control, which operate more slowly. Even though the operations of these two processing systems do not map cleanly onto distinct regions of the brain, and although the two systems often operate cooperatively and in parallel (Weber and Johnson 2009), Kahneman (2011) argues convincingly that the distinction between Systems 1 and 2 helps to make clear the tension between automatic and largely involuntary processes and between effortful and more deliberate processes in the human mind. Psychological research over the past decade has documented the prevalence of System 1 processes in the intuitive assessment of risk, depicting them as essentially effort-free inputs that orient and motivate adaptive behavior, especially under conditions of uncertainty (Finucane et al. 2000; Loewenstein et al. 2001; Peters et al. 2006).

Interestingly, recent work in neuroeconomics has shown that decisions under ambiguity are processed in qualitatively different ways from decisions under risk. Namely, different brain regions encode choice options and mediate the decision, depending on whether the decision is made under conditions of risk or ambiguity. More specifically, choice under ambiguity involves greater activation of brain regions associated with affective responses, in particular fear (Hsu et al. 2005). This result suggests that risk and ambiguity are processed in different ways and that ambiguous information is not simply first reduced to the expected level of risk. A visual analogy representing one psychological understanding of ambiguity is provided in Figure 1. The ambiguous image can be interpreted as either a candlestick or two faces in profile. As the 
viewer can verify, we are capable of switching back and forth between seeing either the candle holder or the two faces, but we can only see one image at a time; we cannot see a combination of the images. Applying this analogy to decisionmaking under ambiguity, ambiguous choice options have multiple probability distributions of outcomes, with each having different implications for choice, and we seem to consider one at a time, instead of reducing the multiple probabilities into one "average."

\section{Second departure from economic models - the outcome dimension}

In addition to treating probability assessment differently from economists, psychologists also stress that uncertainty may exist on the outcome dimension as well as over the likelihood of known events occurring. That is, there may be uncertainty about what the range of possible outcomes is or how catastrophic possible outcomes might be (Taleb 2007).

Consistent with this idea, psychologists have identified two psychological risk dimensions that influence people's intuitive perceptions of risk. The first factor, dread risk, captures emotional reactions to hazards such as nuclear reactor accidents or nerve gas accidents, that is, things that make people anxious because of a perceived lack of control over exposure to these events and because their consequences may be catastrophic. The second factor, unknown risk, refers to the degree to which a risk is seen as new, with a perceived lack of control due to unforeseeable consequences (for example, use of DNA technology). These two dimensions have been shown to influence perceptions of health and safety risks in ways common across numerous studies in multiple countries and to explain differences between the risk perceptions of members of the general public versus those of technical experts (Slovic 1987). Responsiveness to these factors shows that the human processing system maps both the catastrophic outcome risk and the uncertainty risk of future events into affective responses and represents risk as a feeling rather than as a statistic (Loewenstein et al. 2001), consistent with System 1 processing.

The fact that dread and the unknowability of a risk increase risk perception provides an explanation for the moderating effect of familiarity on risk perception, holding constant objective information about the probability distributions of possible outcomes (Weber, 
Siebenmorgen, and Weber 2005). Intuitively, familiarity is associated with knowledge: knowing a certain product, game, person, or environment gives rise to the feeling of familiarity. Empirical research shows that familiarity not only breeds liking, it also breeds greater comfort, reducing dread and feelings of risk and increasing the feeling of control (Weber, Siebenmorgen, and Weber 2005). This association may be legitimate, but it may also be spurious. For instance, familiarity and reduced perception of risk may simply be due to a familiar name, as for a stock widely discussed in the financial press or a stock of a local firm (see Huberman 2001; for a survey see Barberis and Thaler 2003). But it may also be a result of personal experience with the risky option (for example, 20 years of working in a chemical plant). Interestingly, familiarity also moderates the effects of ambiguity on choice. The Ellsberg paradox (Ellsberg 1961) revealed that most decisionmakers are not only risk averse but also ambiguity averse, preferring wellspecified probabilities ("risk") to ambiguous probabilities. However, Heath and Tversky (1991) demonstrated that ambiguity aversion is not present when decisionmakers believe they are familiar with and thus have perceived expertise with the domain of choice. Many members of the general public think of themselves as experts in domains such as sports or the stock market and therefore do not shy away from choice options with ill-defined probabilities, in fact preferring them to equivalent financial lotteries with well-specified probabilities.

In sum, psychology views risk perception as an intuitive rather than an analytic response. This intuitive evaluation is influenced by associations and emotional responses, which in turn are influenced by familiarity. The more familiar a product, stock, or procedure is, the greater the liking and the lower the dread or feeling that it is unknown, even if the objective probability information about possible outcomes (whether exact or not) remains unchanged. This results in lower perception of risk, which leads to a greater involvement in the risky or ambiguous activity, such as greater investment in the stock market.

\section{The role of perceived control}

Investment decisions and risk perception are central topics in behavioral finance, and familiarity is recognized in that literature as one of several important factors in determining 
investors' behavior. Two other important factors are overconfidence and the feedback mechanisms between individual confidence and the economy.

\section{Combined effect}

These factors are all related and, in fact, all contribute to perceived control and often the illusion of control, which is known to affect perceptions of risk. We argue that perceived control is a key concept in understanding mania and panic, as the need for control is a basic human need that contributes to optimism bias and affects risk perception more generally. Lack of control is therefore a violation of a basic need and will trigger episodes of panic and retreat to the safe and known.

The illusion of control refers to the human tendency to believe we can control or at least influence outcomes, even when these outcomes are the results of chance events. For example, individuals often believe they can control the outcome of rolling a pair of dice in a game of craps - throwing the dice hard for large numbers and softly for low numbers (Langer 1975). Most situations outside of casinos involve a combination of skill and chance, but in such situations the illusion of control also induces people to overestimate their degree of control over adverse consequences, believing, for example, that driving is a safer means of transportation than air travel, contrary to accident statistics (Slovic 1987).

Originally defined by Langer as "an expectancy of a personal success probability inappropriately higher than the objective probability would warrant" (Langer 1975), illusory control has since been implicated in a variety of behaviors in which individuals feel inappropriately confident in either their skills or their ability to predict future outcomes, given the circumstances. It has received attention in stock market behavior and financial decisionmaking (Shefrin 2000; Shiller 2000/2005) and in portfolio diversification strategies (Fellner 2009). In financial markets, overconfidence has been tied to excess volatility, as stocks overreact to private information (Daniel, Hirshleifer, and Subrahmanyan 1998) and to poor performance (Barber and Odean 2001). 
The illusion of control is more commonly found in familiar situations, in situations where feedback emphasizes success rather than failure, in situations associated with the exercise of skill (for example, situations that provide involvement in choice and competition (Langer and Roth 1975)), and in stressful situations, including financial trading (Fenton-O'Creevy et al. 2003). Social psychologists argue that the illusion of control is adaptive, since it motivates people to persist at tasks when they might otherwise give up and because there is evidence that it is more common in mentally healthy than in depressed individuals (Taylor and Brown 1988).

The illusion of control is the outgrowth and faulty overgeneralization of the human ability to predict our physical and social environment, a fundamental accomplishment that has helped homo sapiens be one of the most successful species on planet Earth. The search for patterns and predictive relationships is an ability that is inborn, automatic, and nonconscious, and its ubiquity gives rise to superstitious beliefs, including the illusion of control (Langer 1975). Given its value in the process of predicting our environment, the belief in our ability to control events has become a basic human need (Maslow 1954). Persistent failures to have such belief can lead to depression and learned helplessness (Seligman 1975), while having a sense of control is associated with better health (Plous 1993, p. 172).

\section{Control and uncertainty}

Perceptions of uncertainty and choice under uncertainty are both influenced by the sense of control. When people feel in control they act as if they faced risk (left column of Table 2) rather than uncertainty (right column), and they are more willing to take on risk/uncertainty, probably because they overestimate risk when they do not feel in control. It is therefore important to determine the objective situational factors and subjective internal perceptions and beliefs that trigger the perception of control and associated confidence on the one hand, and the perception of lacking control and associated panic on the other hand. The next subsection provides some answers to these questions.

\subsection{Decisions from description versus decisions from experience}




\section{Third departure from economic models-Sources of risk information}

While economists do not distinguish between different sources of information on the probability distributions of choice options, behavioral research has shown important differences in the way people make decisions when information about risky or uncertain choice options comes from repeated personal experience rather than from a statistical (numeric or graphic) description of possible outcomes and their likelihood (Weber, Shafir, and Blais 2004).

This distinction between learning from experience versus learning from description has received recent attention because ostensibly identical information about events and their likelihoods can lead to very different perceptions and actions (Hertwig et al. 2004) because different psychological processes are engaged. Learning from repeated personal experience involves associative and often affective processes that are fast and automatic-the same processes involved in risk perception and perceived control-while learning from statistical descriptions requires analytic processing and cognitive effort. Perhaps for this reason, when given the choice between attending to information provided in the form of statistical summaries or to information provided by personal experience, people are more likely to pay attention to personal experience, and its impact dominates statistical information, even though the latter is often far more reliable (Erev and Barron 2005).

Decisions from description are described well by prospect theory (Tversky and Kahneman 1992), which is based on hundreds of studies of choices between described, one-shot, risky options, typically money lotteries. In such choices, decisionmakers tend to overweight the impact of small-probability events, especially when such events have large positive or negative valence (for example, a 0.001 chance of making $\$ 5 \mathrm{M}$, or a 0.005 chance of brain damage as a side effect of vaccination against measles). In contrast, decisions from experience follow classical reinforcement learning that gives recent events more weight than distant events (Weber, Shafir, and Blais 2004). Such updating is adaptive to dynamic environments where circumstances might change. Because rare events (for example, large financial losses) have a smaller

probability of having occurred recently, they tend on average to have a smaller impact on the decision than their objective likelihood of occurrence would warrant. When they do occur, 
however, they have a much larger impact on related decisions than warranted by their probability. This makes learning and decisions based on experience more volatile across respondents and past outcome histories than learning and decisions based on description (Yechiam, Barron, and Erev 2005). These reinforcement learning models and their predicted, more-volatile responses to small-probability risks seem to describe the general public's (and perhaps also some domain experts') dynamic and fluctuating reactions to small-probability risks far better than rational choice models or their psychological extensions such as prospect theory.

\section{Experience and control}

As mentioned previously, perceived control is influenced by outcome feedback, and the illusion of control is more likely to occur in contexts that emphasize success rather than failure (Langer and Roth 1975). Hence, learning from experience is important for perceived control. When people learn from experience, the reinforcement learning models described above predict that in favorable contexts (that is, environments with largely positive feedback, albeit some small risk of sizable losses) individuals will underweight the probability of losses and will grow overconfident in their ability to control losses, appearing to act in increasingly risk-seeking ways. Conversely, in unfavorable environments, we expect individuals to overweight the probability of losses and underestimate their ability to control such losses, appearing to act in increasingly risk-averse ways. There is indeed evidence indicating that individuals draw different lessons from experience than from description, especially when small-probability events are involved (Hertwig et al. 2004).

If associations with risks and resulting emotional responses arise from personal experience, they should differ significantly across individuals and groups as a function of personal history or socioeconomic circumstances. Several recent economic studies show exactly this: personal experience, such as growing up during a recession, has a long-term effect on economic behavior, including risk-taking, in the expected direction (Malmendier and Nagel 2011), and personal experience with the Great Recession of 2008 seems to shift confidence in homeownership (Bracha and Jamison 2012). Interestingly, there is evidence that experience with 
a recession has an effect on perceived degree of personal agency in determining success (Giuliano and Spilimbergo 2009), which is an important component of the perception of control. Other work has documented the effect of exposure to stressors, such as violent conflict, on economic preferences, in particular risk-taking (for example, Voors et al. forthcoming). Moreover, Malmendier and Nagel (2011) show that more recent experiences have the strongest effect, as is suggested by reinforcement learning (Weber, Shafir, and Blais 2004).

In sum, there is evidence indicating that people learn differently from experience than from description, with recent experience being most influential. Since the perception of control is history- or path-dependent, with greater likelihood of illusory control in the face of continued positive feedback, we expect increased perception of control given a long and recent sequence of favorable experiences. The longer and the better a pattern in recent history is, the greater the sense of control and the lower the perceptions of risk on the part of financial decisionmakers, and the riskier their exhibited choices and behavior appear to an outside observer.

\subsection{Perceived control, confidence, and panic}

\section{Confidence and mania}

Extended periods of successful investment decisions (that is, successful investment in bull markets, like the real estate bubble leading up to the 2008 Great Recession) give rise to feelings of excessive confidence. As discussed above, learning from experience, with its overemphasis on recent events and associated underweighting of small-probability risks, will reduce perceptions of the risk of investment actions that may have sizable objective loss potential. Attribution biases, for example, the tendency to attribute positive outcomes to personal investment skill, but negative outcomes to bad luck (Zuckerman 1979; Van den Steen 2002) contribute to the growing feeling of perceived control and associated reduced perception of risk.

In addition to learning processes at the individual level, social processes also contribute to financial behavior leading up to bubbles. Social comparisons provide incentives to keep up with those who reap benefits from perhaps questionable actions, both for ordinary investors 
(Schoenberg 2007; Schoenberg and Haruvy 2009) and for sophisticated investors. Kindleberger observed that during the dot-com bubble, social comparisons among venture capitalists resulted in investors' fearing being left behind (Kindleberger and Aliber 1978/2005). Another level of social amplification is provided by the financial media's coverage of investment successes and the causal stories built around them. Examples of such stories include the wide range of laudatory articles and books on the East Asian economies during the late 1980s and early 1990s, including a 1993 World Bank report titled “The East Asian Miracle.” Investment success fosters an emotional sense of safety and control, which investors justify to themselves and others by developing models or less formal stories of how things work. Having a model or "story" of the world is argued to be important in forming bubbles and to result in surprising crises (Shiller 2000/2005; Akerlof and Shiller 2009; Reinhart and Rogoff 2009).

\section{Panic}

Events suggesting that existing beliefs of control are illusory-when individuals or groups realize that they can no longer predict and hence control important (financial) events and outcomes in their lives-lead to panic, a strong negative emotion designed to motivate protective action. Such emotional reactions can be seen as an adaptive early warning system, evolution's way of jolting us out of our habitual way of doing things, counteracting our strong status quo bias (Samuelson and Zeckhauser 1988).

Black swan events, that is, the occurrences of something previously considered outside of the plausible range of events, signal that our current mental model of the risky or uncertain processes is inadequate or faulty (Taleb 2007). Hence, a reassessment of the risks and benefits of different choice options is necessary and short-term protective action may be required. Such a signal indicating that we have an incorrect model of the world and hence may not be able to predict or control consequences essentially reactivates the second psychological risk dimension identified by Slovic et al. (Slovic et al. 1981; Slovic 1987) (see Table 2, right column), fear of the unknown, which previously may have been assuaged by repeated successful personal experiences with the risky choice options. 
We deal with the potential threats of new and complex environments or technologies by forming a mental model of how the new technology and/or environment works. This model gets tested by repeated exposure, that is, by sampling these risky options and observing resulting outcomes. The absence of negative consequences and the occurrence of essentially predicted outcomes make us confident in our understanding of how things work and our ability to control adverse consequences. Both the complexity and riskiness of these new technologies or environments may be underestimated in the face of positive feedback. When we subsequently receive a signal contradicting our model, we no longer know what to do, and panic results.

A nonfinancial example of panic-inducing events that shake our sense of understanding a technology and hence upend our feeling of control over possible adverse catastrophic consequences is nuclear power accidents. Interestingly, it was U.S. public opposition to nuclear power in the 1950s that triggered the investigation of the psychological risk dimensions discussed above. At that time, the nuclear power industry commissioned psychologists to explain to them why public perception of the relative risk of nuclear power generation (compared with other fuel choices like coal) was so different from engineering models and estimates. A better understanding of public fears led to a re-description of energy choices that resulted in greater acceptance of nuclear power, and during the 1960s and 1970s the number of reactors under construction globally increased continually. The Three Mile Island accident in 1978, a partial nuclear meltdown, was a significant turning point in the global development of nuclear power, despite the fact that only small amounts of radioactive gases and radioactive iodine were released into the environment (International Atomic Energy Association 2008). Public panic about our insufficient understanding and control over a dangerous and complex technology was expressed and amplified by the media. who used sorcerer's apprentice story lines in movies like "The China Syndrome." The 1986 Chernobyl accident reinforced concern about gaps in our understanding of the risks of the technology, and the recent Fukushima Daiichi accident showed that existing backup plans to provide coolant to reactor cores had dangerous gaps under national disaster conditions. 
The feeling of panic, an extremely aversive emotion, motivates us to turn away from dangerous new technologies or environments and toward the old and familiar, whether this means embracing a known technology, like coal-generated power with its known risks of climatechanging emissions, or moving our assets from mortgage-backed securities to gold.

Just as social processes amplify individual responses and reactions during periods of perceived control and (over)confidence, social processes also amplify the perceived loss of control and feelings of panic (Kasperson et al. 1988). During the East Asian financial crisis, for example (see Table 3), previously glowing media coverage of the East Asian Miracle gave way to new buzzwords such as "crony capitalism," "spontaneous privatization," and "destabilizing speculation" (Kindleberger and Aliber 1978/2005, p. 158; Knoop 2008). In addition to economic consequences, the psychological impact of the new "junk bond status" of sovereign debt in South Korea, Thailand, and Malaysia, after being downgraded by Moody's in December 1997, contributed to creditor panic and bank runs.

Evidence that panics give rise to a redesign of existing mental models of complex technologies and environments comes from the fact that recent financial crises appear to affect subsequent events. Once the mental model is challenged, perceived control is lost and investors seem to retreat from all markets where they held a similar mental model. That is, investors shift from perceived control to perceived lack of control, which leads them to avoid similar investment environments, even if the triggering event resulting in loss of control originated in a different market.

\section{Example}

The East Asian Crisis in the late 1990s and the following crises in Russia and Brazil are a nice illustration of such overgeneralization. Psychology tells us that risk and uncertainty are, at least in part, emotional constructs influenced by the causal models of the world people form to fit their personal experience. The longer these models are confirmed or not violated by the data, the more confident people grow in their model and the lower their perceptions of risk or uncertainty. Hence, the longer the period of reassuring feedback, the greater the increase in 
risk-taking and the higher the likelihood of falling into an illusion of control. Importantly, the state of feeling in control is discrete: people either feel in control (with the risk of illusory feeling of control) or they feel lack of control. The sense of control or predictability collapses when a casual model is violated, especially if the violation follows a long sequence of reassuring experiences and if there is no alternative model people can rely on. The response in such an event tends to be a panic response, reflected in retreat from all markets governed by the violated model, until a new model emerges. These elements were all present in the East Asian Crisis: For several years preceding the crisis, East Asian countries experienced consistently high annual GDP growth and high growth in their stock markets. In the five Asian countries most strongly impacted by the crisis, average GDP growth was between 5 and 10 percent per year, and the stock market increased between 256 and 934 percent in just a few years since 1987 (see Table 3). This several-years-long positive record led to large foreign capital inflows and the “Asian Miracle" label (Kindleberger and Aliber 2005, 156-158). The label reflected investors' confidence and their mental model of the investment environment in Asia, namely, the belief that the "emerging economies" of East Asia were a miracle, shifting from a negative to a positive investment environment and the belief that it would continue to be positive. Indeed, when the crisis hit East Asia it was regarded as "...the least anticipated financial crisis in years" (Radelet and Sachs 2000).

Importantly, the "Asian Miracle" label also reveals that Asian countries were regarded as a single group. When the crisis began in Thailand in July 1997, it quickly spread to other East Asian countries, with a rapid reversal of private capital inflows. As Radelet and Sachs (2000) write, "the Asian crisis can be understood as a 'crisis of success,' caused by a boom of international lending followed by a sudden withdrawal of funds. At the core of the Asian crisis were large-scale foreign capital inflows into financial systems that became vulnerable to panic." "By early 1997," they add, "markets expected a slowdown-even a devaluation crisis-in Thailand, but not in the rest of Asia. Indicators as late as the third quarter of 1997 did not suggest a financial meltdown of the sort that subsequently occurred." 
Our account of the perception of control fits well: investors formed a mental model applicable to all Asian countries, and they grew confident in this model of a "miracle" as the Asian economies experienced years of abnormal positive economic performance, confirming the "miracle" model. Once one of these countries-Thailand-collapsed, it violated investors' favorable mental model regarding (all) Asian countries; investors lost their sense of control and cashed out in other Asian markets, leading to the Asian meltdown.

Following the Asian crisis, Russia and then Brazil were also subject to currency attacks that resulted in financial crises. The Russian and Brazilian experiences can be thought of as a contagion from the Asian crisis, due to investors' overstating the perceived similarities between these countries. If investors think of countries in broad categories - say, developing countriesa crisis that shakes investors' mental model of the markets or perceived control in investment in one country may spill over to other countries in the domain. Indeed, Corsetti, Pesenti, and Roubini (1999), discussing the spread of the crisis to Brazil, noted that "investors overstated the perceived similarities, in terms of macro conditions, between Brazil and Russia, thus overlooking structural differences within the highly heterogeneous group of 'emerging' economies." Krugman summarized this in an interview prior to the Russian devaluation (Lahóz 1998): "If you look at the domestic and foreign balances, you realize that the Brazilian economy is decelerating. Under normal circumstances, you could consider adopting expansionary monetary measures. The necessary side effect is currency depreciation. But one thing is certain: now is not the time to devalue the exchange rate. Not with such unstable financial markets. In my view, the main contagion of the Asian crisis in Brazil is psychological: the financial market today associates devaluation with lack of control and catastrophe. Because of that, Brazil must wait until everything settles down. There's a funny side: if the mark falls, there will be no sign of panic in Germany. But all the countries that are lumped together with the Asians have to be very careful in the present moment. Unfortunately, that's still the case of Brazil". 


\section{Economic models of financial panics}

How do we think about (aspects of) panic within economics? In this section we briefly describe macroeconomic models of informational cascades, sunspots, macroeconomic frictions, and fire sale externalities that, although not models of panic per se, capture aspects of panic, including its unexpected timing and/or the resulting drastic, amplified, coordinated actions. We briefly describe these models by pointing out the mechanisms suggested in these models that allow for panic-type behavior. We show that these mechanisms do not capture the psychological insights suggested in this paper, and we suggest possible ways to incorporate the psychological insights into economics, by focusing on models of individual decisionmaking.

Models of partial informational cascades, such as Lee (1998), capture the drastic and sudden change of actions during financial crises. In fact, Lee's model is consistent with the stylized facts of price movement before a crash, namely, a boom, followed by euphoria, then a trigger event and panic. The idea is that agents receive private information, but due to transaction costs, some of this private information will be hidden, that is, not reflected in prices. This information is hidden because some agents with weak signals find it unprofitable to trade. However, once an agent receives a signal strong enough to warrant different action than previously taken, his or her action reveals that information to all. This revelation triggers action by all agents who previously received similar yet weaker information-that is, a signal that was not strong enough to warrant an action and hence was kept hidden. The greater the amount of hidden information accumulated in the market, the stronger the reaction to the triggering signal will be. If there is enough hidden information, a triggering signal will generate large avalanches that can be viewed as "panic." In other words, "panic" in this model is rooted in information aggregation and follows the revelation of new information.

Models of multiple equilibria with the possibility of sunspots capture some aspects of panic as well, although in a very different fashion. To illustrate this we use the seminal paper by Diamond and Dybvig (1983), which focuses on bank runs, but is applicable more broadly. Specifically, a bank's liabilities are deposits, which are liquid and yet are invested in projects 
(for example, profitable technology) that are not as liquid. The bank can credibly pay high returns on deposits (higher than attainable by just keeping the money at home), even if these deposits are withdrawn before the project is completed, only the amount that is withdrawn early is limited. Diamond and Dybvig (1983) show that in such an environment, there are two possible equilibria - a good one and a bad one. In the good equilibrium, only those who must withdraw early do so, the project is completed, and everyone is better off. In the bad equilibrium, depositors panic en masse and create a run on the bank by withdrawing early. In this case, due to the mismatch of liquidity, even a healthy bank will fail and some depositors will lose their money. Ending up in the good or bad equilibrium is a matter of coordination, since if everyone withdraws early the best response is to withdraw money as well. Yet, if there is no bank run, the best response is to keep the money on deposit till maturity (unless one must withdraw early). Hence, this is an example of a situation in which, in the absence of new information, a bank run or, more generally, a panic can occur.

Models of multiple equilibria of the type illustrated above capture the possibility of "panic" in the sense of "fright without a cause." Yet they do not explain why coordination on a particular equilibrium occurs. "Sunspots"-unrelated events or signals that trigger a different equilibrium-are assumed to be arbitrary. Nevertheless, we believe that such models are a natural entry point to incorporate possible influences of the perception of control and that the events that trigger a switch in equilibrium may not be as arbitrary as they appear to economists. Signals that appear to cause individuals to converge on a specific equilibrium may not be signals of coordination per se; rather, they may spark a common perception of control or lack of control. One can think of modeling a process to capture the evolution of (the illusion of) control; signals or events that affect dimensions important for control, along the lines we lay out in this paper, would likely trigger a change of equilibrium, while signals that do not play on important dimensions for control would not affect the market.

The logic behind the mechanism of a bank run - that is, a situation in which, due to a liquidity mismatch, a fear of a bank run is self-fulfilling - is applicable to firms and countries as well. If lenders fear a firm will be unable to meet its obligations, they will not renew or make new loans 
to the firm. This could be devastating, even for a healthy firm, especially if the firm relies on short-term loans to finance long-term projects or holds otherwise illiquid assets. An idea along these lines is captured in models of frictions or fire-sale externalities, which illustrate mechanisms that amplify or help to generate business fluctuations. The amplification effect may be seen as panic, and we use two seminal papers in this strand of the literature-Bernanke and Gertler (1989) and Bernanke, Gertler, and Gilchrist (1999) - to illustrate the basic idea. In these models there are borrowers (entrepreneurs) and lenders, but only the entrepreneurs know the realized return on capital. The lenders, if they wish to verify the true return on capital, need to accept an "auditing" or agency cost (for example, the cost of bankruptcy). These costs are relevant only in bankruptcy, and the lender must be compensated for this risk. Quite intuitively, the more the entrepreneur invests in the project with internal funds, the lower the chance of bankruptcy (that is, the lower the risk of being unable to meet the loan's terms), and hence the less the lender needs to be compensated for this risk. Yet if there is a negative shock that harms the borrower's cash flow or the value of the firm's assets so that the firm has less money to invest, the chance of bankruptcy increases, and external funds become more expensive. This leads to lower lending, less investment in capital, and lower productivity in future periods, which then leads to further reductions in lending and investment. Hence, the existence of agency costs creates a feedback loop that helps to propagate bad (and symmetrically good) times, where bad times are reflected in either bad balance sheets of the borrower or a negative productivity shock in the economy. A similar effect, in which a temporary shock may generate large and persistent movements in output, can also be captured using durables as collateral (for example, Kiyotaki and Moore 1997).

The above models, although representing only a very small number of studies, reflect the main mechanisms considered in the economic literature to capture some of the aspects present in episodes of panic. The mechanisms considered in the literature are problems in information aggregation (partial informational cascades), coordination (sunspots), and frictions or fire-sale externalities that give rise to a feedback mechanism that amplifies an initial temporary shock. The insight proposed in this paper - that a perceived loss of predictability and control gives rise 
to panics - is not represented in these models. However, the proposed dynamics surrounding the perceived loss of control can inform these models. As previously suggested, it is possible that the seemingly arbitrary and irrelevant signal that triggers coordination on a bad equilibrium (that is, the sunspot) is not as arbitrary as it seems and may need to have specific characteristics. In particular, it may need to be an event that falsifies agents' mental model or understanding of the world, leading to a perceived loss of control-a sudden fright without necessarily an economic cause.

\section{How can we incorporate the insights from psychology to economic models?}

There are two important elements in the psychological account of panic: (1) recognition of two regimes: (a) perceived control and (b) perceived lack of control and (2) learning from experience. We usually feel in control, and this is the relevant regime for existing decisionmaking models. Panic occurs when we slip into the second, lack-of-control regime in which agents do not know what to do. We suggest below three possible manners of addressing panic within economics: (1) by modeling panic as a switch from optimism to pessimism, (2) by using models with two layers of uncertainty, in which the additional layer captures the two perceived control regimes, and (3) by using experience-based models of reasoning.

\section{Switching between optimism and pessimism}

Switching between two extreme views of the world-either focusing on the best- or the worstcase scenario-can be captured using the variational preference framework (Maccheroni, Marinacci, and Rustichini 2006). The variational preference framework subsumes the max-min expected utility model of Gilboa and Schmeidler (1989) and the multiplier preferences model of Hansen and Sargent (2001). In this approach the individual takes the best action, given the worst-case scenario-a play against a malevolent nature-which is constructed to capture ambiguity aversion. Although it is presented as a model of ambiguity aversion, Bracha and Brown (2012) show that this approach has the alternative interpretation of pessimism, by assuming that the worst case is the most likely one. Furthermore, considering the best-case scenario instead-a max-max expected utility-gives rise to Bracha and Brown's affective 
decisionmaking model (ADM), a model of optimism bias. Interestingly the two approaches can be represented as a maximization of a composite function $\mathrm{J}(\mathrm{U}(\mathrm{x}))$, where $\mathrm{J}$ is a function over the utility of consumption $\mathrm{U}(\mathrm{x})$. When $\mathrm{J}(\cdot)$ is convex, the ADM representation-optimism-arises; when $\mathrm{J}(\cdot)$ is concave, variational preferences - pessimism - arise.

Uncertainty is represented by a set of possible probability distributions where the agent does not know which distribution is the correct one. In other words, the agent has several models of the world but does not know which model is the true one. Panic, as we describe it, occurs when the current model of the world, based on past experience and especially on recent past experience, is shattered. An example would be an optimistic agent who thinks that the world functions according to the best-case scenario; once an event or signal contradicts this rosy view of the world, it triggers a fundamentally different view, a feeling that the worst may happen, meaning extreme pessimism. We can therefore think of panic as a trigger that moves the agent from convexity to concavity of the function $\mathrm{J}(\cdot)$, that is, from optimism to pessimism.

Note that switching from confidence to panic or, as suggested above, from optimism to pessimism, is reminiscent of the notion of shifts in investor sentiment in finance. Investor sentiment relates to different regimes of control, in our terminology. In their model of investor sentiment, Barberis, Shleifer, and Vishny's (1998) investors shift between two different models of the world, in which investors believe that earnings are either mean-reverting or continuing a trend. We similarly suggest that investors switch between an optimistic and a pessimistic model of the world in which perceived control allows putting most decision weight on the best-case scenarios and where the absence of perceived control mandates putting most decision weight on the worst-case scenarios.

Under this approach, the set of possible probability distributions (or models of the world) remains unchanged. The difference is whether the agent focuses attention on the best-case or the worst-case scenario. Another way to represent our approach is to think of the set of possible probability distributions (over future states of the world) that the agent considers as his or her model of the world. Any sequence of realizations not consistent with probability distributions 
in the set would violate the agent's model of the world. In other words, panic may be captured by the need to introduce an additional layer of uncertainty: uncertainty over which sets of possible distributions need to be considered. It is possible to think of a hierarchy of sets, where smaller sets represent better knowledge and greater confidence as to which is the true model of the world. When a sequence of realizations is inconsistent with the set that the agent is currently considering, a panic is triggered. In this case, panic can be represented as a switch to considering a larger set of probability distributions, possibly even the full universe of distributions. Considering a larger set of possible probability distributions reflects the agent's loss of confidence that he or she holds the true model of the world. Here, panic is represented by the size of the set considered, not by switching among decision rules or ambiguity attitudes.

Another framework to address panic that may be most fruitful in application to macroeconomics, is the "fragile beliefs" framework of Hansen and Sargent (2001). In this framework there are two sources of uncertainty: uncertainty due to model misspecification and uncertainty over which model to consider. While in their paper Hansen and Sargent are concerned with consumption growth, we can adopt their framework to a situation in which the background model selection captures the two regimes-perceived control and perceived lack of control. The psychological view of panic also suggests that the weights put on the two possible models or regimes by individuals are not continuous, but rather a 0-1 function.

\section{Experience-based learning}

We have argued that an important difference between the economic and psychological approaches to risk perception is the recognition of a difference between learning from experience and learning from description. Evidence suggests that learning from experience dominates if both types of learning are present. Given the importance of experience in general, and in contributing to the illusion of control and the destruction of perceived control, models of experience-based learning such as Gilboa and Schmeidler's (1995) case-based decision theory are also relevant. In addition, recent studies such as Fuster, Hebert, and Laibson's (2011) 
"natural expectations" show the potential relevance of recent data in explaining asset prices dynamics.

Case-based decision theory suggests that decisions are based on past experiences: each agent has a memory set of cases, namely, all past events, the action taken at each event, and its outcome. Each such past event is judged in terms of similarity to the current decision situation. Based on the memory set and similarity function, the decisionmaker takes the action that is expected to yield the best outcome. Gayer and Gilboa (2012) present a model of switching between rule-based and case-based reasoning. Taking this framework, we can think of rulebased reasoning as the state in which the agent has a model of the world, analogous to the regime of control in our terminology.

\section{Discussion}

In this paper, we propose a psychological account of financial panics in the tradition of providing psychological motives for economic behavior and applying dual process theory, in which System 1 associative and emotional processes influence and often compete with System 2 analytic processes. At both the individual and collective levels this results in responses that are overly influenced by recent events and thus overly volatile relative to a rational analysis of encountered situations.

Specifically, we propose a central role for the need for control, a human motivation so important for survival in complex and potentially dangerous environments that the search for prediction and for causal mental models of phenomena has become automatic and ubiquitous. Causal mental models for nonscientists typically take the form of stories, one of Akerlof and Shiller's (2009) animal spirits - an insightful acknowledgement even if somewhat mislabeled (in that stories are not emotions).

The explanatory power of stories or narratives is typically tested with some confirmation bias (Klayman and Ha 1987), leading to overreactions in either direction, meaning overconfidence in a benevolent environment or overreaction in the face of apparent malevolence. Fluctuations 
from irrational exuberance to panic and back again contrast with a much more moderate, rational, Bayesian updating of beliefs in the face of changing evidence. Part of this difference is no doubt due to the difference in processes assumed to be used by the rational versus the descriptive account of belief updating in the face of changing evidence. The rational account represents belief in the form of probability distributions over possible states of the world and assumes that updating is done in a continuous fashion. The descriptive account proposed in this paper represents belief more discretely, for example, in the form of a small number of competing narratives (typically two) and assumes that people alternate between these two. Such alternation is analogous to the perception of ambiguous visual images like the one shown in Figure 1. We are capable of switching back and forth between seeing a candlestick or two faces in profile, but we cannot see both at once, nor any image halfway in between. The common practice of substituting a small number of discrete scenarios for a continuous distribution of possible probability distributions of future states of the world in many strategic planning contexts, from oil exploration (Schoemaker 1991) to climate change mitigation (Morita et al. 2001) suggests that the processing of discrete states of the world is a more natural process for even relatively sophisticated human decisionmakers.

Instances of overreaction in the direction of irrational exuberance and panic must have some evolutionary advantage, given their continued existence despite repeated experience of their inaccuracies. The illusion-of-control literature makes this argument for the overconfidence that results from the excessive perception of control, suggesting that overconfidence may make us persist at tasks that we might otherwise abandon. An argument for an evolutionary advantage can also be made for self-protective actions taken in response to panic or excessive pessimism, since the System 1 response of taking self-protective action enables System 1 and 2 processes to safely collect additional information to generate a new narrative that makes the environment predictable again. Future research may want to examine the contribution of overconfidence and panic to individual and public welfare, and the way these two conflicting animal spirits keep each other in check. 
Given the important supporting role played by the illusion of control in triggering periods of exuberance and panic outlined in this paper, it is useful to speculate about situations that may enhance or reduce the illusory perception of control or illusory beliefs in a lack of control and their potentially negative consequences. Gaining a better understanding of the preconditions of panic may enable us to better predict instances of panic or to design choice environments that maximize the positive consequences and minimize the negative consequences of automatic System 1 processes that are hard to inhibit (Johnson et al. in press). The connection between decisions based on experience and the illusion of control (with implications for reduced perception of risk and increased apparent risk-taking) suggests that long periods of positive feedback enhance perceived control and confidence in the causal narrative believed to underlie the experienced success. The greater the confidence in the ability to predict and control outcomes and risks, the larger will be the panic when such assumptions are proven wrong. Hence, we would expect a negative signal to have a higher likelihood of causing panic when agents both hold a clear testable (simple) model and their recent experience is a long sequence of positive outcomes. The complexity of the situation or phenomenon will most likely interact with these dynamic processes; that is, one would expect it to take longer to feel control over more complex phenomena, but also expect a greater likelihood of the perception of loss of control and panic for complex phenomena. The illusion of control has been shown to be greater under stressful conditions. Under stressful conditions, to which complexity contributes, the need to gain a feeling of control by adopting a narrative is greater than under more benign circumstances, as doing so is a way to manage such stress (Fisher 1986). Yet once such a narrative is proven wrong, the feeling of lack of control would likely be stronger, since the stress and complexity make it more difficult to find an alternative narrative and regain control.

Little research exists on individual differences in susceptibility to the illusion of control or susceptibility to panic. Our account suggests that more-successful people may be more susceptible to it, but this hypothesis awaits testing. Somewhat contrary to this hypothesis, there is some evidence of the negative consequences of the illusion of control in financial trading. One study followed 107 traders in four London banks and found that those with the highest illusion 
of control performed the worst, as measured by managers' ratings of performance and by total remuneration (Fenton-O'Creevy et al. 2003).

Are there any actions that policymakers or institutional systems could take to prevent or minimize reactions of panic during financial crises? For example, are there different types of messages that could induce different degrees of feeling in control? The account of panics proposed in this paper suggests that a crucial role that policymakers could play would be to provide investors with new, compelling narratives about the market or about a commodity in crisis, to supplant the narrative that has shattered existing narratives (for example, the belief that some banks, such as Lehman Brothers, are too big to fail). Providing new, simple, positive narratives that provide guidance to action could fill the vacuum left by disproven narratives that, in the absence of intervention, give rise to panic and narratives of gloom and doom. 


\section{References}

Akerlof, George A., and Robert J. Shiller. 2009. Animal Spirits: How Human Psychology Drives the Economy and Why it Matters for Global Capital. Princeton, NJ: Princeton University Press.

Barber, Brad M. and Terrance Odean. 2001. "The Internet and the Investor." Journal of Economic Perspectives 15(1):41-54.

Barberis, Nicholas, Andrei Shleifer, and Robert Vishny. 1998. "A Model of Investor Sentiment." Journal of Financial Economics 49(3):307-343.

Barberis, Nicholas, and Richard Thaler. 2003. "A Survey of Behavioral Finance" In Handbook of the Economics of Finance, Volume 1, ed. G.M. Constantinides, M. Harris and R. Stulz, 1053-1128. Amsterdam: Elsevier Science B.V.

Bernanke, Ben, and Mark Gertler. 1989. "Agency Costs, Net Worth, and Business Fluctuations." The American Economic Review 79(1):14-31.

Bernanke, Ben, Mark Gertler, and Simon Gilchrist. 1999. "The Financial Accelerator in a Quantitative Business Cycle Framework" In Handbook of Macroeconomics, Volume 1, ed. J.B. Taylor and M. Woodford, Chapter 21. Amsterdam: Elsevier Science B.V.

Bracha, Anat, and Donald J. Brown. 2012. “Affective Decision Making: A Theory of Optimism Bias" Games and Economic Behavior 75(1):67-80.

Bracha, Anat, and Julian C. Jamison. 2012. "Shifting Confidence in Homeownership: The Great Recession" B.E. Journal of Macroeconomics, forthcoming.

Brunnermeier, Markus K. 2008. "Bubbles.” In The New Palgrave Dictionary of Economics Online. Palgrave Macmillan. Available at http://www.dictionaryofeconomics.com/article?id=pde2008_S000278.

Corsetti, Giancarlo, Paolo Pesenti, and Nouriel Roubini. 1999. "What Caused the Asian Currency and Financial Crisis?" Japan and the World Economy 11(3):305-373.

Daniel, Kent, Hirshleifer, David, and Subrahmanyam, Avanidhar. 1998. "Investor psychology and security market under- and overreactions." The Journal of Finance, 53: 1839-1885.

Diamond, Douglas W., and Philip H. Dybvig. 1983. “Bank Runs, Deposit Insurance, and Liquidity." Journal of Political Economy 91(3):401-419. 
Einhorn, Hillel J. 1986. “Accepting Error to Make Less Error.” Journal of Personality Assessment 50(3):387-95.

Ellsberg, Daniel. 1961. "Risk, Ambiguity, and the Savage Axioms." Quarterly Journal of Economics 75(4):643-669.

Erev, Ido and Greg Barron. 2005. “On Adaptation, Maximization, and Reinforcement Learning Among Cognitive Strategies." Psychological Review 112(4):912-931.

Fellner, Gerlinde. 2009. Illusion of control as a source of poor diversification: Experimental evidence. The Journal of Behavioral Finance, 10, 55-67.

Fenton-O'Creevy, Mark, Nigel Nicholson, Emma Soane, and Paul Willman. 2003. “Trading on Illusions: Unrealistic Perceptions of Control and Trading Performance." Journal of Occupational and Organizational Psychology 76(1):53-68.

Finucane, Melissa L., Ali Alhakami, Paul Slovic, and Stephen M. Johnson. 2000. "The Affect Heuristic in Judgments of Risks and Benefits." Journal of Behavioral Decision Making 13(1):1-17.

Fisher, Shirley. 1986. Stress and Strategy. London, England: Lawrence Erlbaum Associates.

Foote, Christopher L., Kristopher S. Gerardi, and Paul S. Willen. 2012. "Why Did So Many People Make So Many Ex Post Bad Decisions? The Causes of the Foreclosure Crisis." Federal Reserve Bank of Boston Public Policy Discussion Paper 12-2. Available at http://www.bostonfed.org/economic/ppdp/2012/ppdp1202.pdf.

Fuster, Andreas, Benjamin Hebert, and David Laibson. 2011. "Natural Expectations, Macroeconomic Dynamics, and Asset Pricing." NBER Macroeconomics Annual 26:1-48.

Gayer, Gabrielle and Itzhak Gilboa. 2012. "Analogies and Theories: The Role of Simplicity and the Emergence of Norms." Working Paper. Available at http://itzhakgilboa.weebly.com/uploads/8/3/6/3/8363317/gayer_gilboa_analogies_and_theories. pdf.

Gilboa, Itzhak, and David Schmeidler. 1989. "Maxmin Expected Utility with Non-Unique Prior." Journal of Mathematical Economics 18(2):141-153.

Gilboa, Itzhak, and David Schmeidler. 1995. "Case-Based Decision Theory” The Quarterly Journal of Economics 110 (3): 605-639. 
Giuliano, Paola, and Antonio Spilimbergo. 2009. "Growing up in a Recession: Beliefs and the Macroeconomy." Working Paper 15321. Cambridge, MA: National Bureau of Economic Research.

Goldstein, Itay. Forthcoming. "Fundamentals or Panic: Lessons from the Empirical Literature on Financial Crises." In Encyclopedia of Financial Globalization, ed. Gerard Caprio. Amsterdam: Elsevier.

Hansen, Lars Peter and Thomas J. Sargent. 2001. "Robust Control and Model Uncertainty." American Economic Review 91(2): 60-66.

Heath, Chip and Amos Tversky. 1991. "Preference and Belief: Ambiguity and Competence in Choice under Uncertainty." Journal of Risk and Uncertainty 4(1):5-28.

Hertwig, Ralph, Greg Barron, Elke U. Weber, and Ido Erev. 2004. “Decisions from Experience and the Effect of Rare Events in Risky Choice." Psychological Science 15(8):534-539.

Holtgrave, David R., and Elke U. Weber. 1993. “Dimensions of Risk Perception for Financial and Health Risks." Risk Analysis 13(5):553-558.

Huberman, Gur. 2001. “Familiarity Breeds Investment.” Review of Financial Studies 14 (3):659־ 680.

Hsu, Ming, Meghana Bhatt, Ralph Adolphs, Daniel Tranel, Colin F. Camerer. 2005. Neural Systems Responding to Degrees of Uncertainty in Human Decision-Making." Science 310(5754):1680-1683.

Hume, David. 1748/1999. An Enquiry concerning Human Understanding, ed. Tom L. Beauchamp. Oxford: Oxford University Press.

International Atomic Energy Association. 2008. "50 Years of Nuclear Energy." Retrieved December 29, 2008.

Johnson, Eric J., Suzanne B. Shu, Benedict G.C. Dellaert, Craig Fox, Daniel G. Goldstein, Gerald Häubl, Richard P. Larrick, John W. Payne, Ellen Peters, and David Schkade, et al. 2012 "Beyond Nudges: Tools of a Choice Architecture." Marketing Letters 23(2):487-504.

Kahneman, Daniel. 2003. "Maps of Bounded Rationality: Psychology for Behavioral Economics." American Economic Review 93(5):1449-1475.

Kahneman, Daniel. 2011. Thinking, Fast and Slow. New York: Farrar, Straus and Giroux. 
Kasperson, Roger E., Ortwin Renn, Paul Slovic, Halina S. Brown, Jacque Emel, Robert Goble, Jeanne X. Kasperson, and Samuel Ratick. 1988. “The Social Amplification of Risk: A Conceptual Framework." Risk Analysis 8(2):177-187.

Keynes, John M. 1936. The General Theory of Employment, Interest and Money. London: Macmillan (reprinted 2007).

Kindleberger, Charles P., and Robert Z. Aliber. 2005. Manias, Panics, and Crashes: A History of Financial Crises, 5th Edition. New York: John Wiley \& Sons, Inc.

Kiyotaki, Nobuhiro, and John Moore. 1997. "Credit Cycles." Journal of Political Economy 105(2):211-248.

Klayman, Joshua, and Young-Won Ha. 1987. "Confirmation, Disconfirmation and Information in Hypothesis Testing." Psychological Review 94 (2):211-228.

Knight, Frank H. 1921. Risk, Uncertainty, and Profit. Washington, D.C.: Beard Books (reprinted 2002).

Knoop, Todd A. 2008. Modern Financial Macroeconomics: Panics, Crashes, and Crises. Malden, MA: Blackwell Publishing.

Krugman, Paul. 1998. "What Happened to Asia?" Working Paper. Available at http://web.mit.edu/krugman/www/DISINTER.html.

Krugman, Paul. 1999. “Capital Control Freaks: How Malaysia Got Away With Economic Heresy." Slate 27 September 1999. Available at

http://www.slate.com/articles/business/the_dismal_science/1999/

09/capital_control_freaks.html.

Lahóz, André. August 5, 1998. "Não precisamos perder o sono." Exame. English translation available at http://www.pkarchive.org/global/exame.html.

Langer, Ellen J. 1975. "The Illusion of Control." Journal of Personality and Social Psychology 32(2):311-328.

Langer, Ellen J., and Jane Roth. 1975. "Heads I Win, Tails it's Chance: The Illusion of Control as a Function of the Sequence of Outcomes in a Purely Chance Task." Journal of Personality and Social Psychology 32(6):951-955.

Lee, In Ho. 1998. "Market Crashes and Informational Avalanches." Review of Economic Studies 65(4):741 -759 . 
Loewenstein, George, Elke U. Weber, Christopher K. Hsee, and Ned Welch. 2001. "Risk as Feelings." Psychological Bulletin 127(2):267-286.

Maccheroni, Fabio, Massimo Marinacci, and Aldo Rustichini. 2006. "Ambiguity Aversion, Robustness, and the Variational Representation of Preferences" Econometrica 74(6):1447-1498.

Maslow, Abraham H. 1954. Motivation and Personality. New York: Harper \& Row.

Malmendier, Ulrike, and Stefan Nagel. 2011. "Depression Babies: Do Macroeconomic Experiences Affect Risk Taking?" Quarterly Journal of Economics 126(1):373-416.

Moreno, Ramon. 1998 “What Caused East Asia's Financial Crisis?” Federal Reserve Bank of San Francisco Economic Letter 98-24. Available at http://www.frbsf.org/econrsrch/wklyltr/wklyltr98/el98-24.html.

Morita, T., et al. 2001. "IPCC Emissions Scenarios and the SRES Process" In IPCC TAR WG3, ed. B. Metz, O. Davidson, R. Swart, and J. Pan. Climate Change 2001: Mitigation, Contribution of Working Group III to the Third Assessment Report of the Intergovernmental Panel on Climate Change, Cambridge University Press. 2.5.1.1. Available at http://www.grida.no/publications/other/ipcc_tar/?src=/climate/ipcc_tar/wg3/080.htm.

Peters, Ellen, Daniel Västfjäll, Tommy Gärling, and Paul Slovic. 2006. "Affect and Decision Making: A 'Hot' Topic.” Journal of Behavioral Decision Making 19(2):79-85.

Plous, Scott. 1993. The Psychology of Judgment and Decision Making. McGraw-Hill.

Radelet, Steven and Jeffrey Sachs. 2000. “The Onset of the East Asian financial Crisis," In Currency Crises, ed. Paul Krugman, 105-153. Chicago: University of Chicago Press.

Reinhart, Carmen M. and Kenneth Rogoff. 2009. This Time is Different: Eight Centuries of Financial Folly. Princeton, NJ: Princeton University Press.

Rosengren, Eric S. January 14, 2011. “Two Key Questions about the Economic Recovery." Remarks at the New England Mortgage Expo, hosted by the Connecticut Mortgage Bankers Association and The Warren Group. Available at http://www.bostonfed.org/news/speeches/rosengren/2011/011411/index.htm.

Samuelson, William, and Richard Zeckhauser. 1988. "Status Quo Bias in Decision Making." Journal of Risk and Uncertainty 1(1):7-59.

Schoenberg, Eric. 2007. "Beauty is in the Eyes of the Other Beholders: Strategy Matching in Financial Markets." PhD dissertation, Department of Psychology, Columbia University. 
Schoenberg, Eric, and Ernan Haruvy. 2009. "Relative Wealth Concerns in Asset Markets: An Experimental Approach." Working Paper. Available at

http://www1.gsb.columbia.edu/mygsb/faculty/research/pubfiles/3153/Relative\%20Wealth\%20a nd\%20Asset $\% 20$ Markets.pdf.

Schoemaker, Paul, J.H. 1991. “When and How to Use Scenario Planning: A Heuristic Approach with Illustration." Journal of Forecasting 10(6):549-564.

Seligman, Martin E.P. 1975. Helplessness: On Depression, Development, and Death. San Francisco: W. H. Freeman.

Shefrin, Hersh. 2000. Beyond Greed and Fear. Cambridge, MA: President and Fellows of Harvard.

Shiller, Robert J. 2005. Irrational Exuberance, 2nd Edition. New York: Random House Inc.

Slovic, Paul. 1987. “Perception of Risk." Science 236(4799):280-285.

Slovic, Paul, Baruch Fischhoff, Sarah Lichtenstein, F.J.C. Roe. 1981. "Perceived Risk: Psychological Factors and Social Implications." Proceedings of the Royal Society of London. Series A, Mathematical and Physical Sciences 376(1764):17-34.

Taleb, Nassim N. 2007. The Black Swan: The Impact of the Highly Improbable. New York: Random House.

Taylor, Shelley E., and Jonathon D. Brown. 1988. "Illusion and Well-Being: A Social Psychological Perspective On Mental-Health." Psychological Bulletin 103(2):193-210.

Tversky, Amos, and Daniel Kahneman. 1992. "Advances in Prospect Theory: Cumulative Representation of Uncertainty." Journal of Risk and Uncertainty 5(4):297-323.

Van den Steen, Eric. 2002. "Skill or Luck? Biases of Rational Agents." MIT Sloan Working Paper No. 4255-02. Available at

http://ssrn.com/abstract=319972.

Voors, Maarten, Eleonora Nillesen, Philip Verwimp, Erwin Bulte, Robert Lensink, and Daan van Soest. Forthcoming. "Does Conflict Affect Preferences? Results from Field Experiments in Burundi." American Economic Review.

Weber, Elke U. 2010. "Risk Attitude and Preference." Wiley Interdisciplinary Reviews: Cognitive Science 1(1):79-88. 
Weber, Elke U., and Eric J. Johnson. 2009. "Mindful Judgment and Decision Making." Annual Review of Psychology 60:53-86.

Weber, Elke U., Sharoni Shafir, and Ann-Renee Blais. 2004. "Predicting Risk-Sensitivity in Humans and Lower Animals: Risk as Variance or Coefficient of Variation." Psychological Review 111(2):430-445.

Weber, Elke U., Niklas Siebenmorgen, and Martin Weber. 2005. “Communicating Asset Risk: How Name Recognition and the Format of Historic Volatility Information Affect Risk Perception and Investment Decisions." Risk Analysis 25(3):597-609.

The World Bank. 1993. "The East Asian Miracle: Economic Growth and Public Policy." World Bank Policy and Research Report. Available at http://econ.worldbank.org/external/default/main?pagePK=64165259\&theSitePK=469372\&piPK= 64165421\&menuPK=64166093\&entityID=000009265_3970716142516.

Yechiam, Eldad, Greg Barron, and Ido Erev. 2005. "The Role of Personal Experience in Contributing to Different Patterns of Response to Rare Terrorist Attacks." Journal of Conflict Resolution 49(3):430-439.

Zuckerman, Mirion. 1979. "Attribution of Success and Failure Revisited, or: The Motivational Bias is Alive and Well in Attribution Theory." Journal of Personality 47(2):245-287. 